\title{
Stage IIIC Breast Cancer AJCC v7
}

National Cancer Institute

\section{Source}

National Cancer Institute. Stage IIIC Breast Cancer A/CC V7. NCI Thesaurus. Code C88377.

Stage IIIC includes: Any T, N3, M0. N3: Metastases in ipsilateral infraclavicular (level III) axillary lymph nodes(s) with or without level I, II axillary lymph node involvement; or in clinically detected ipsilateral internal mammary lymph node(s) with clinically evident level I, II axillary lymph node metastases; or metastases in ipsilateral supraclavicular lymph node(s) with or without axillary or internal mammary lymph node involvement. M0: No clinical or radiog raphic evidence of distant metastasis. MO includes MO(i+). (AJCC 7th Ed.) 